\title{
Investigating the effects of sudden column removal in steel structures
}

https://doi.org/10.1515/nleng-2021-0024

Received Jun 13, 2021; accepted Sep 20, 2021.

\begin{abstract}
Since the effect of the irregularity in height of medium and tall structures has a great influence on lateral behavior of structures and it also affects the design of the sections, in this study, various scenarios of sudden column removal in different locations of steel structures with and without geometric irregularities in height have been investigated. The Alternate load Path Method (APM), Nonlinear Dynamic Analysis (NDA), and OpenSees software were used to investigate 10,15 and 20-story buildings with three types of irregularity in four different column removal scenarios.

The results show that increasing the irregularity in height increases the response of the structure. Also, the response of the structure to the sudden removal of columns in short buildings is greater than high-rise buildings. In other words, as the floors and elements in the buildings decreases, the potential for the progressive failure, increases.
\end{abstract}

Keywords: Progressive collapse, irregularity in height, nonlinear dynamic analysis

\section{Introduction}

Progressive Collapse (PC) is the chain spread of an initial local failure from element to element resulting, eventually, in the collapse of the whole structure or a disproportionate large part of it $[1,2]$. One of the mechanisms of structural failure, which has drawn increasing attention over the past few decades, is referred to as Progressive Collapse (PC). One or several structural members suddenly fail, every load redistribution causing in turn the failure of the other structural elements and the building is progressively destroyed. Buildings must be designed so that they are capable of limiting the local failure by inte-

Ali Esfandiari Fard, Morteza Biklaryan, Department of Civil Engineering, Chalous Branch, Islamic Azad University, Chalous, Iran *Corresponding Author: Heydar Dashti Nasserabadi, Department of Civil Engineering, Chalous Branch, Islamic Azad University, Chalous, Iran, E-mail: Heidardashti843@gmail.com grating structural members, improving energy redistribution and redistributing loads (by creating alternative load paths) and resisting unusual loads. In USA, General Services Administration [3] presented a practical regulation to decrease the potential of Progressive Collapse (PC) in federal buildings. Unified Facilities Criteria, Department Of Defense of U.S [4] provided regulations to design existing buildings. Jalalilarijani et al. [5] assessed the effects of column removal in structures with different bracing systems using the Linear Static Analysis (LSA). Tavakoli and Rashidi Alashti [6] investigated Moment Resisting Frame (MRF) steel structures designed based on seismic codes against Progressive Collapse (PC). They concluded that in contrast with 3D models, 2D models are more sensitive to base shear reduction and column loss. Furthermore, the structure is more robust after occurring collapse at middle bay than in a corner column removal situation. $\mathrm{Kr}$ ishna Chaitanya [7] proposed solutions for the structures exposed to Progressive Collapse (PC). The studies show that this type of collapse takes place more in Japan, South Korea, India and other Asian countries. Mahmoud et al. [8] surveyed the potential of Progressive Collapse (PC) due to seismic loads in Moment Resisting Frame (MRF) and Braced Frames. Rahnavard et al. [9] examined Progressive Collapse (PC) in tall steel composite buildings by nonlinear analysis. Based on the result of their study, side case removal in both Moment Resisting Frame (MRF) and moment with centrically braces was more critical. Kolesnik and Kolesnik [10] studied analytically the regulatory frame work on the building against Progressive Collapse (PC) and concluded they are incomplete and need more refinement and if the owners decide to reconstruct their buildings, they should consume more time in addition to significant direct financial costs. Kordbagh and Mohammadi [11] studied the Influence of seismicity level and height of building on progressive collapse resistance of steel frames. Kiakojouri et al. [12] studied the progressive collapse assessment of steel moment-resisting frames using static and dynamic incremental analyses.

Although there have been numerous investigations regarding progressive collapse in various structures, some topics have remained overlooked one of which is the effect of irregularity in height in assessing the progressive collapse potential in mid-rise and high-rise buildings. Ac- 
cordingly, this paper intends to conduct a comprehensive investigation concerning the effects of sudden column removal by using nonlinear dynamic push down analyses. The investigated cases, analysis methods and results are provided as following.

\section{Modeling and analysis}

Since the aim of this research is surveying the effects of sudden column removal considering the irregularity effects in mid-rise and high-rise structures, first, threedimensional 10,15 and 20-story structures were modelled and designed linearly at first. SAP2000 [13] software used to design the mentioned structures. Structures (after linear modelling), are subjected to gravity load after linear modelling based on Iranian loading standards. The spectral dynamic analysis method is used for the lateral loading and structural analysis in accordance with Buildings standard- 2800 [14]. For the lateral loading, it is assumed that the type of soil beneath of the structures is "Type 3" and the level of earthquake hazard is "high". The height of the floors is equal and it is considered 3 meter. The structures in the $\mathrm{X}$ direction have six, 4-meter spans and in the $\mathrm{Y}$ direction have five, 5-meter spans as shown in Figure 1.

In order to consider the effects of geometric irregularities in height, it is assumed that the structures are recessed in height in three cases, and three irregular states are considered for the structure.The intended models for irregular 20-story structures are shown in Figure 2. In the selection of irregularity effects, it is tried to consider irregular geometric effects in the structure simultaneously with decreasing mass in the upper floors. In all models of 10 , 15 , and 20 -story buildings, case 1 indicates the gradual removal of one span in the first step, and in the subsequent step, the gradual removal of two spans on one side of the upper floors of structures. Case 2 indicates the sudden removal of two spans of the upper floors on one side and case 3 shows the gradual removal of one and two spans on both sides in the height of the structure.

Span reduction for the 15-story building is illustrated in Figure 4. Although the main aim of this figure is to represent the finite element model in the OpenSees software, span reduction for making irregularity is obvious in this figure and is applied to the model in 9th and 13th floors. For the 10-story building, span reduction has occurred in the 6th and 8th floors.

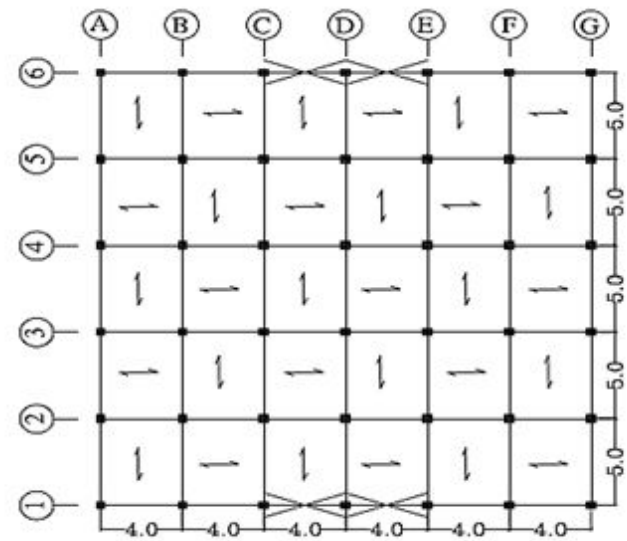

Figure 1: Elementary plan of structural floors

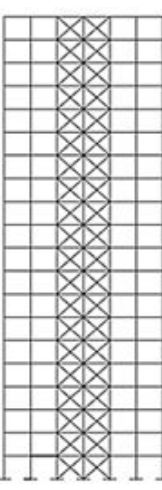

(a)

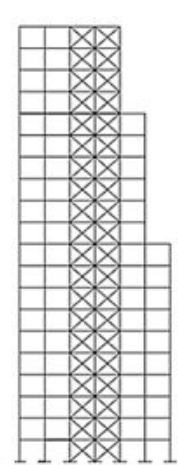

(b)

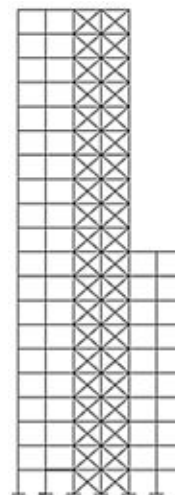

(c)

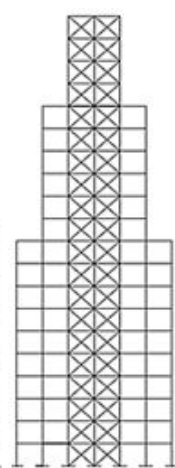

(d)
Figure 2: View of regular and irregular models in height for a 20storey model, (a) Regular model; (b) Irregular model of case 1; (c) Irregular model of case 2; (d) Irregular model of case 3

\subsection{Modeling and designing}

The Load Resistance Factor Design (LRFD) method is used to design structures. ST37 steel is assumed to be used to design the structures according to the AISC360 [15]. Linear parameters and loading values required for modelling and designing of the desired structures in this research are shown in Table 1. In spectral dynamic analysis, the design spectrum is selected based on the standard design spectrum of 2800 codes. In nonlinear design and modelling of the structures, the amount of dead and live load are considered same for all structural models. Dead and live load of the building roof are considered same to that of other floors. Snow load with the value of $1.5 \mathrm{KN} / \mathrm{m}^{2}$ is also considered in the design and modelling of the structure for the building roof. 
Table 1: Modeling and designing parameters.

\begin{tabular}{l|l|l}
\hline Unit & Value & Parameter \\
\hline $\mathrm{KN} / \mathrm{m}^{2}$ & 6 & Dead load \\
\hline $\mathrm{KN} / \mathrm{m}^{2}$ & 2 & Live Load \\
\hline $\mathrm{KN} / \mathrm{m}^{2}$ & $2.4 \mathrm{e}+5$ & Yield Stress \\
\hline $\mathrm{KN} / \mathrm{m}^{2}$ & $2.88 \mathrm{e}+5$ & Expected Yield Stress \\
\hline $\mathrm{KN} / \mathrm{m}^{2}$ & $2 \mathrm{e}+8$ & Modulus of Elasticity, $\mathrm{E}$ \\
\hline- & 0.3 & Poisson ratio \\
\hline $\mathrm{KN} / \mathrm{m}^{3}$ & 8 & Mass per Unit Volume \\
\hline
\end{tabular}

After modelling and analysis, 10, 15 and 20 storey structures have been designed Structures designed in the $\mathrm{X}$ direction have a dual concentrically braced system with a special ductility and in the Y direction have a moment resisting frame with a special ductility. In this paper, the column sections are considered as square boxes, beams are symmetric I section, and braces are standard UNP sections. The selected sections are shown in Table 2. In this table, hw-tw represents the dimensions of the web and bftf shows the dimensions of the flange in the I-shape sections of the beam. The dimensions of the sections are in millimetre (mm).

\subsection{Progressive collapse analysis}

Progressive Collapse (PC) modelling does not require complex cyclic behaviour [16]. There are two issues in discussing the sudden removal of a column and the Progressive Collapse (PC) scenario. The first matter is related to the location of column loss and the second one is the loading condition and how to suddenly remove the columns. There are various methods for structural analysis in the sudden removal of columns [17]. According to the General Services Administration (GSA) standard, Nonlinear Dynamic Analysis (NDA) method is one of the most useful methods to evaluate the Progressive Collapse (PC) potential in order to simulate the sudden removal of the column [18]. In this method, the structure is firstly analyzed under gravity load. Subsequently, the load on the desired element in the structure is determined in the structure and then applied in the opposite direction to its upper node after the element removal. In order to perform a Nonlinear Dynamic Analysis (NDA), the gravity load with a load combination of $\mathrm{DL}+0.25 \mathrm{LL}$ reaches its real value linearly within five seconds. To eliminate vibrations, the load remains constant for two seconds and then suddenly, the reaction of the deleted column will be removed from the structure as shown in Figure 3 (a) and (b) and the resulting vibrations are eliminated as a vertical displacement of the re- moved column and the time is presented as an Nonlinear Dynamic Analysis (NDA), General Services Administration (GSA) (2003). This curve shows the dynamic response of the structure to the sudden removal of the column.

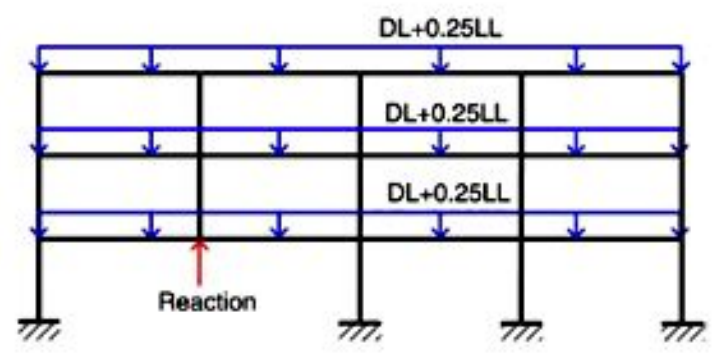

(a)

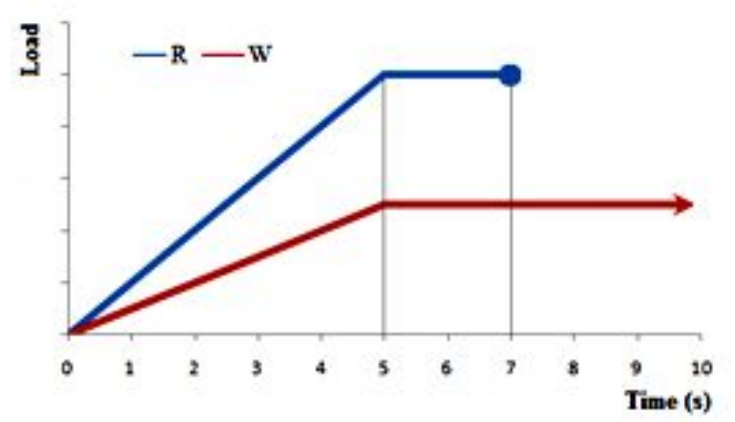

(b)

Figure 3: Nonlinear Dynamic Analysis (NDA) according to the General Services Administration (GSA) Standard (GSA (2003)), (a) Load Pattern; (b) Time History of Gravity Loads

There are numerous software applications for Nonlinear Dynamic Analysis (NDA) today. OpenSees is one of the finite element software which is available to users in open source mode [19]. This software has many capabilities for nonlinear modeling and dynamic analysis. In this software, it is possible to delete any loading or delete any element during the analysis. Due to the capabilities of this software, an attempt has been made to model the sudden column removal scenario in a realistic way by combining the method of Alternate load Path Method (APM), suggested in the General Services Administration (GSA) standard, and method of this researches. it is supposed that the gravitational loading is applied linearly with a combination of DL + 0.25LL within five seconds, as shown in Figure 3 (without the R curve). Then like w curve, in Figure 3 remains constant and continues as a function of time. To model the sudden removal of a column, it is assumed that in the seventh second of the analysis, the desired columns are removed from the structure and the structure begins to 
Table 2: Characteristics of structural section

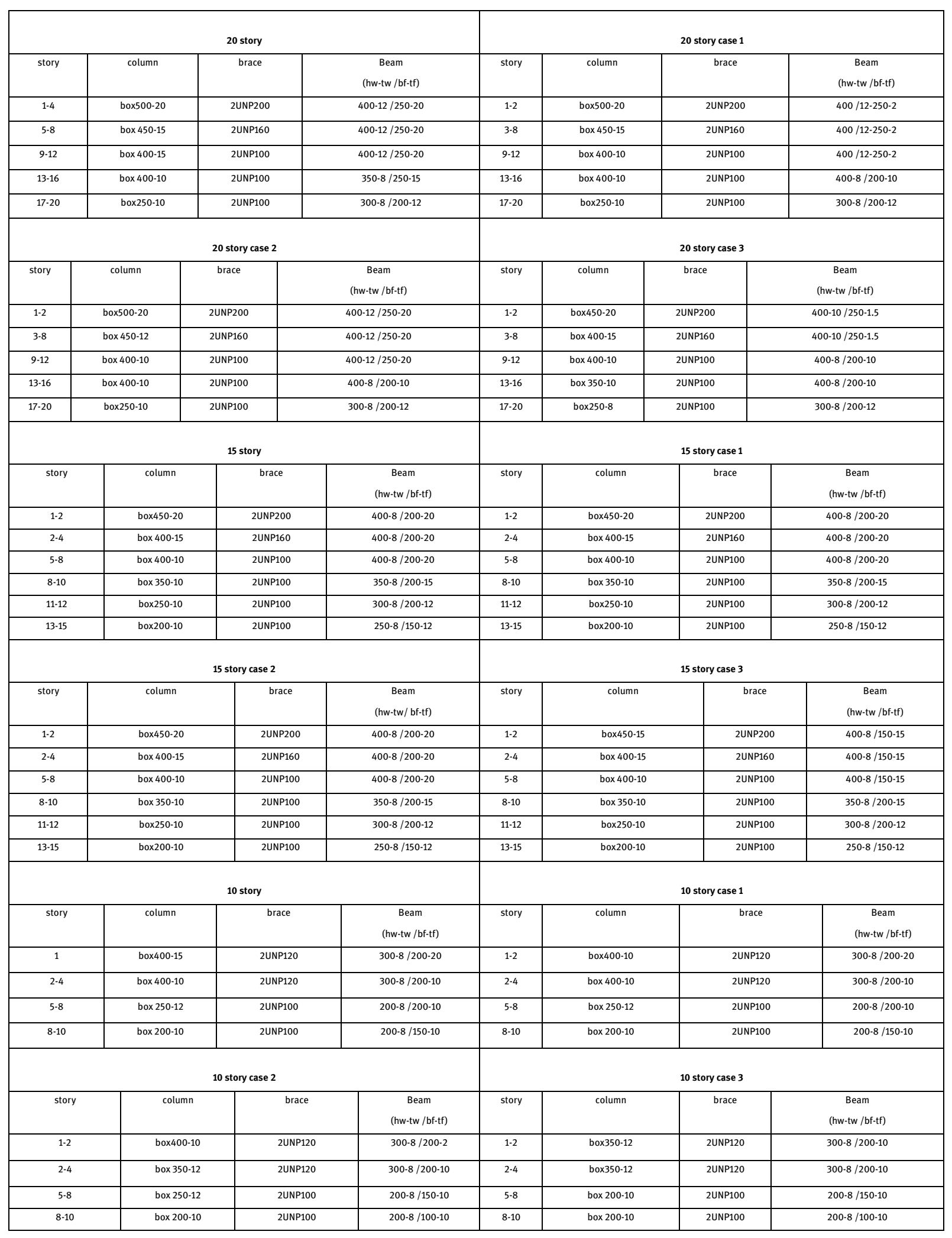


vibrate. As stated in this study, for the Nonlinear Dynamic Analysis (NDA), OpenSees software is used. Also, steel01 materials are defined using the ST37 steel characteristics. For the nonlinear modeling of beams and columns, nonlinear Beam-Column element are used. P-Delta effects are also considered in the elements modeling. In OpenSees, there are three methods for assigning local axes: linear, P$\Delta$, and Corotational. The use of Corotational is a comprehensive method to take into account both the effects of P- $\Delta$ and the effects of large deformations. Therefore, since the effects of P- $\Delta$ are important in the progressive collapse, the Corotational method has been used to consider its effects, in which both the effects of P- $\Delta$ and the effect of large deformations have been considered.

Steel01 material is utilized from the library of OpenSees software for modelling steel elements of the current study. Material specifications mentioned in Table Iare used for the definition of this material. The finite element model with distributed plasticity in form of fiber with 10 integration points is used for modelling the elements. The secondary stiffness coefficient is assumed to be equal to 0.02. Therefore, the model used for the elements is based on distributed plasticity with 10 integration points in which the behaviour of each fiber is based on the Stress-Strain relationship and it is considered with respect to Steel01 material.

There are several methods for modeling the plastic behavior of materials and elements. Two common methods in these modeling are the use of concentrated and distributed plasticity model. In the concentrated plasticity method, the total plastic behavior of the materials is considered in the form of moment-rotation curves in the beams and moment-rotation along with the interaction of the axial force in the columns. In the distributed plasticity method, the properties of the plastic joint are considered as fibers. These fibers can be present along the element or can be considered as dots along the element. These points are defined as integration points. As stated in the OpenSees software manual, the strain hardening coefficient is expressed by a coefficient $b$. This coefficient expresses the ratio of hardening in the plastic area to the initial hardening. This coefficient is usually considered in different sources in the range of 0.01 to 0.05 .

There are two comprehensive methods in the plasticity modeling, the concentrated plastic joint method and the distributed plasticity method [20]. In the concentrated plasticity method, which itself is divided into two methods of force-control and displacement-control, it is assumed that the integration points are located at the critical points of the member. In columns, for example, concentrated plastic joints are placed at both ends of the column where the shear is maximum. These points are considered as two points of integration. In distributed plasticity, which is neither deformation-control nor force-control, but stressstrain relationships are used, in order to reduce the volume of the equations and also maintain accuracy, the other integration points other than the critical points are used. The number of these points in the OpenSees software is maximum ten points, which the equations related to it are determined and used in different ways. The following is a description of these methods.

Nonlinear Beam-Column element is one of the most useful and applicable elements for modelling the nonlinear behaviour of elements which is available in the library of OpenSees software. Properties and formulation of this element exists in the manual of OpenSees software. In this paper 10 points are considered as integration points.

Tolerance for the satisfaction of element compatibility is equal to $10^{-16}$ and the maximum number of iterations to undertake to satisfy element compatibility is assumed as 1 . Additionally, the Corotational Formulation is used for the definition of local axes of this element. Furthermore, sections of this element are defined as fibre type with nonlinear stress-strain relationship according to Steel01 material.

An example of 3D modeling structures in this study is shown in Figure 4.

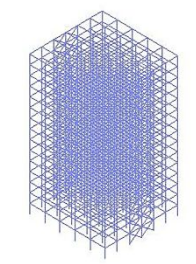

(a)

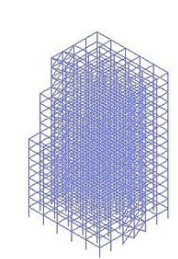

(b)

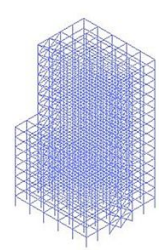

(c)

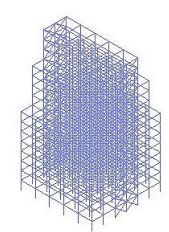

(d)
Figure 4: 15-story structures models in the OpenSees software, (a) 15story; (b) 15story - case 1; (c) 15story -case 2; (d) 15story -case 3

In this study, different situations are considered regarding the local failure position and the sudden column removal scenario. In each structural type, 4 scenarios of column removal are considered. The sudden column removal scenarios are; columns D1 and D3 and G3 on the 6th floor and the column D3 on the 8th floor of the 10-story structure as well as other scenarios including columns D1 and D3 and G3 on the 8th floor and D3 on the 12th floor of the 15-story structure and columns D1 and D3 and G3 on the 10th floor and D3 on the 16th floor of the 20-story structure as shown in Figure 1. 


\section{Review of analysis results}

The sudden column removal scenarios are simulated in the structures after nonlinear modeling of 10, 15 and 20story structures. The gravity load is applied linearly from zero to real value within 5 seconds, and then it stays constant for 2 seconds so that the vibrations caused by the applied loads to the structure are depreciated. In the seventh second, the desired column will be removed from the structure and the analysis continues. For the removed column, the vibrations and vertical deformations of the top point is presented as a function of time in the form of a nonlinear dynamic curve of structure.

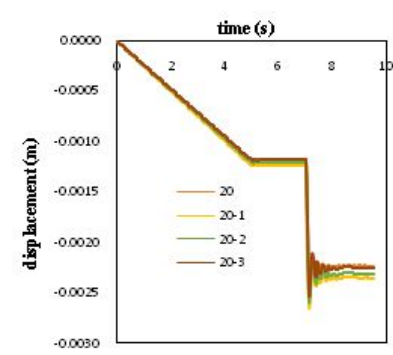

(a)

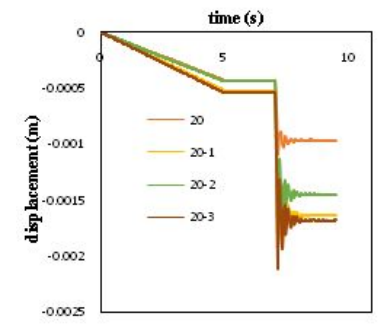

(c)

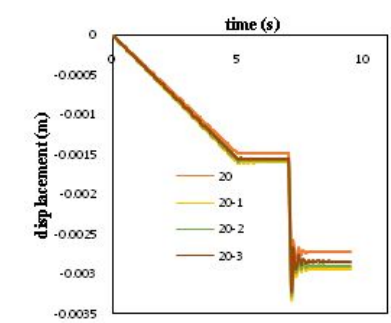

(d)

Figure 5: Nonlinear dynamic curves of 20-story structures, (a) D1$10^{\text {th }}$ Floor; (b) D3-10 th Floor; (c) G3-10 th Floor; (d) D3-16 $6^{\text {th }}$ Floor

In Figure 5, the nonlinear dynamic curves of the 20story structures are shown during the desired column removal scenarios. In this paper, the purpose of the phrase "response of the structure" is the vertical displacement of the removed column's top point in the dynamic push down analysis.

Investigating nonlinear dynamic curves due to sudden column removal scenarios in 20-story structures reveals that firstly, the vertical deformation of the top point of the removed column is a few millimeters, which indicates that the sudden column removal in the high-rise structures creates a minor response to the structure. In fact, the sudden

column removal from the structure will not lead to a Progressive Collapse (PC) in these structures and the structures will not have the potential of total failure due to this sudden removal. Secondly, the study of the irregularity effect in the structure shows that irregularity in 20-story models does not have a significant influence on the structural response. The maximum and final displacements are close to each other in structural models. However, in all column removal scenarios, the 20-story structure has the smallest response. This structure has both the smallest maximum displacement and the least residual response. Also, the column D1-10 ${ }^{\text {th }}$ Floor removing scenario shows that the sudden column removal from the adjacent braces creates the least vibrations in the structure. Also, the results show that the presence of braces in the area of the removed column causes the structure to achieve equilibrium again in a controlled state along with lower vibrations and vibration domains.

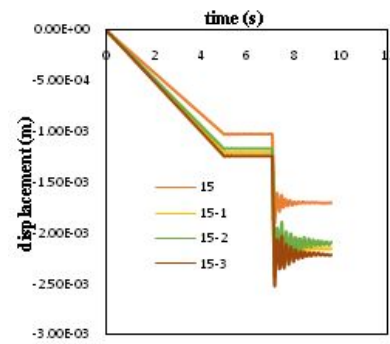

(a)

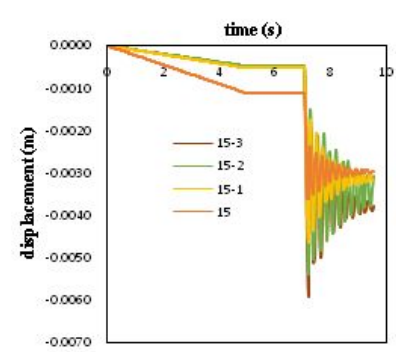

(c)

Figure 6: Nonlinear dynamic curves of 15-story structures, (a) D1-8 ${ }^{\text {th }}$ Floor; (b) D3-8 th $^{\text {Floor; (c) G3-8 }}{ }^{\text {th }}$ Floor; (d) D3-12 ${ }^{\text {th }}$ Floor

Figure 6 shows the nonlinear dynamic curves in the desired scenarios of 15-story structures. Nonlinear dynamic curves of 15-story structures show that in all models, as 20-story structures, a non-irregular structure has the smallest response among other structures. The sudden column removal scenario in regular 15 -storey structure has both the smallest maximum response and sustained re- 
sponse comparing to the other structures. Examination of the place of sudden removal of columns also shows that in the scenario of sudden removal of columnD1- $8^{\text {th }}$ Floor, in addition to the fact that the structure has the lowest response compared to other scenarios, the vibrations caused by the sudden removal of column in this case are less than other scenarios. The column removal response in scenario D3-12 ${ }^{\text {th }}$ Floor shows that the removal of the column in the upper floors increases the response of the structure. In the structural models related to the 15-story structure, the highest response relates to the response caused by removing the column D3-12 $2^{\text {th }}$ Floor in an irregular structure of case 15-3. In the study of irregularity effects, it can be concluded that the presence of irregularities in height can affect lateral loading on modal deformations and shear of the floors. But, in the sudden column removal scenario, lateral load and also lateral behavior of the irregular structures is not significant and the important issue is the ability of the structure to withstand the overload caused by the sudden column removal. The structure with more elements and structural sections, has more ability to withstand excessive loads. Creating the irregularities discussed in this study leads to weight loss in the structure. Decreasing the number of elements in irregular structures firstly reduces the number of structural elements that can be effective in bearing overload caused by the column removal and secondly as the weight of the structure decreases, the structural sections also become weaker and the load bearing capacity decreases.

According to Buildings Standard - 2800 (2004) [14] the design earthquake load for seismic resistant structures is calculated based on the earthquake coefficient multiplied by the structure weight. Since the removal of a portion of structural elements in height would lead to a total weight reduction, it is obvious that the quantity of earthquake force would decrease and the structure would be designed for lower levels of seismic loads. Therefore, it is plausible to achieve weaker structural elements in structures with irregularities in height rather than structures without any irregularity. However, this is not a general rule and can be merely a reason for the reduction of capacity and growth of response in structures with irregularities. Therefore, it can be concluded that the increase of response in irregular structures in height is not due to the lateral behavior, but it is because of the decreasing in the number of elements and the weakening the structural sections.

Figure 7 shows this process for 10-story structures. Investigating the curves of Figure 7 shows that the responses of 10-story structures compared to the 15 and 20-story structures have increased. Therefore, it can be concluded that by reducing the number of floors, the response of the
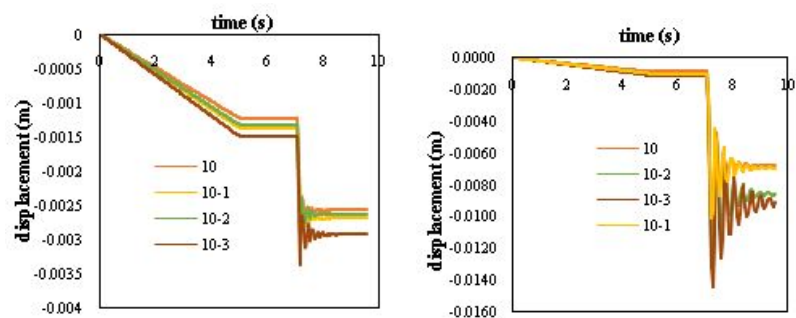

(a)

(b)
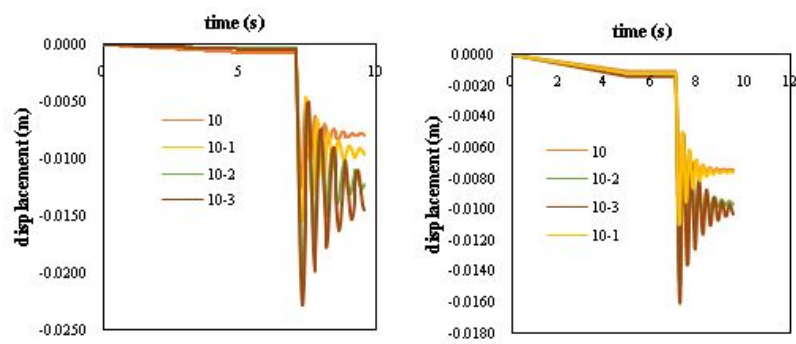

(c)

(d)

Figure 7: Nonlinear dynamic curves of 10-sory structures, (a) D1- $6^{\text {th }}$ Floor; (b) D3-6 $6^{\text {th }}$ Floor; (c) G3-6 ${ }^{\text {th }}$ Floor; (d) D3-8 ${ }^{\text {th }}$ Floor

structure to the sudden column removal increases. In the 10-story models, the highest response of structures relates to the case G3-6. Similar to the 15 and 20-story models, irregular structures have the smallest response and the smallest potential of failure due to the sudden removal of the column. Generally, case 10-3 irregular structures have the highest response to the sudden column removal. The smallest response among all models belongs to the case of removing the column from the braced span. Existences of braces have decreased the highest response and the vibrations because of sudden removal. Increasing the number of spans in the structure has increased the response to the sudden column removal.

\section{Conclusions}

In this study, using nonlinear dynamic analysis, in the structures with height irregularities, the potential for progressive collapse and the response of the structure to the sudden column removal were investigated. The 10-, 15-, and 20-story buildings were modeled and analyzed in a regular and three irregular modes, and the results are presented in the form of dynamic curves (Displacement of the top point of the removed column- Time).

Examination of the results of the analysis shows 
1) The special effect of irregularity in the height of the building is that it causes more lateral load to be applied to the structure and ultimately affects the design of sections and increases the cross section of structural members.

2) As the floors and elements of a building increases, the potential for the progressive collapse decreases. That is, the presence of geometric irregularities such as weight loss increases the response of structures. This increase in the response of the structure increases with decreasing the number of floors so that the 10storey structure (lowest height) with irregularity in height has the highest response and the highest potential for the progressive failure.

3) If the column removal occurs at the bracing opening, the responses are far fewer than non-bracing openings. This means that the safety of the building is greater when the column is removed near the braced opening

4) In all structural models, the sudden column removal did not produce a significant response. This matter indicated that mid-and high-rise structures did not have the potential of Progressive Collapse (PC) due to the column removal.

Funding information: The authors state no funding involved.

Author contributions: All authors have accepted responsibility for the entire content of this manuscript and approved its submission.

Conflict of interest: The authors state no conflict of interest.

\section{References}

[1] Lew H. Best practices Guidelines for Mitigation of Building for progressive collapse. Senior Research Engineer, Building and Fire Research Laboratory, National Institute of Standards and Technology. Gaithersburg. Maryland. U.S.A. 2003;208998611.

[2] Prabowo AR, Cho HJ, Lee SG, Baek SJ, Byeon JH, Bae DM, Sohn JM, Harsritanto BIR. Evaluating structural crashworthiness and progressive failure of double hull tanker under accidental grounding: bottom raking case. Open Eng. 2018;8(1):193-204.

[3] GSA. Progressive collapse analysis and design guidelines for new federal office buildings and major modernization projects. The US General Services Administration. 2003.

[4] UFC-DoD. Unified Facilities Criteria-Department of Defense. Design of buildings to resist progressive collapse. 2005.
[5] Jalalilarijani R, DashtiNasserabadi H, Aghayan I. Progressive collapse analysis of buildings with concentric and eccentric braced frames. Struct Eng Mech. 2017;6:755-763.

[6] Tavakoli HR, RashidiAlashti A. Evaluation of progressive collapse potential of multi-story moment resisting steel frame buildings under lateral loading. Sci Iran. 2013;A(20): 77-86.

[7] KrishnaChaitanya M. Progressive collapse of structures. International Journal of Mechanical Civil and Control Engineering. 2015; 1: 123-129.

[8] Mahmoud YM, Hasan MM, Mourad SA, Sayed, HS. Assessment of progressive collapse of steel structures under seismic loads. Alex Eng J. 2018;57:3825-3839.

[9] Rahnavard R, FathiZadehFard F, Hosseini A, Suleiman M. Nonlinear analysis on progressive collapse of tall steel composite buildings. Case Stud Constr Mater. 2018;8:359-379.

[10] Kolesnik O, Kolesnik D. The calculating the progressive collapse problem in the light of the existing regulatory framework of the Russian Federation. IOP Conf. 2019;698:022-048.

[11] Kordbagh B, Mohammadi M. Influence of seismicity level and height of the building on progressive collapse resistance of steel frames. Struct Des Tall Spec Build. 2017;26:e1305.

[12] Kiakojouri F, Sheidaii MR, De Biagi V, Chiaia B. Progressive Collapse Assessment of Steel Moment-Resisting Frames Using Static-and Dynamic-Incremental Analyses. J Perform Constr Facil. 2020;34(3):04020025.

[13] SAP2000 v17.1.1. Structural analyses and design. Theory Manual. 2015.

[14] Buildings standard-2800. Iranian code of practice for seismic resistant design of buildings. 2004.

[15] AISC360. Specification for structural steel buildings. American Institute of Steel Construction, Chicago (IL). 2010.

[16] Kim T, Kim J. Collapse analysis of steel moment frames with various seismic connections. J Constr Steel Res. 2009;65:1316-1322.

[17] Izzuddin BA, Vlassis AG, Elghazouli AY, Nethercot DA. Progressive collapse of multi-story buildings due to sudden column loss- Part I: Simplified assessment framework. Eng Struc. 2008;30:1308-18.

[18] Qian CZ, Chen CP. Nonlinear Dynamics Analysis for the Taut Inclined Cable Excited by Deck Vibration. Nonlinear Eng. 2017;6(3):241-24.

[19] Luo J, Fahnestock LA, Faveb L. Nonlinear Static Pushover and Eigenvalue Modal Analyses of Quasi-Isolated Highway Bridges with Seat-Type Abutments. Structures. 2017;12:145-167.

[20] Scott MH. Numerical integration options for the force-based beam-column element in OpenSees. Force-Based Element Integration Options in OpenSees. 2011:1-7. 